\title{
Probable Hourly Precipitation and Soil Water Index for 50-yr Recurrence Interval over the Japanese Archipelago
}

\author{
H. Saito ${ }^{1,2}$ and H. Matsuyama ${ }^{2}$ \\ ${ }^{1}$ College of Economics, Kanto Gakuin University, Kanagawa, Japan \\ ${ }^{2}$ Department of Geography, Tokyo Metropolitan University, Tokyo, Japan
}

\begin{abstract}
We produced a preliminary high-resolution probable hourly precipitation $\left(\mathrm{mm} \mathrm{h}^{-1}\right)$ and probable Soil Water Index (SWI) for a 50-yr recurrence interval over the Japanese archipelago from 5-km grid-cell Radar/Raingauge-Analyzed Precipitation (R/A) with a 26-yr time series (1988-2013). To date, the selection and applicability of a probability density function such as the Gumbel distribution (GUM) or the generalized extreme value distribution $(\mathrm{GEV})$ has been investigated mainly from a statistical perspective, whereas this study examines them from the viewpoint of disaster prevention. Results show detailed spatial patterns of the probable hourly precipitation and SWI in Japan with ranges of 17.0-158.0 $( \pm 1.1-51.1) \mathrm{mm} \mathrm{h}^{-1}$ and 82.1-638.6 ( $\left.\pm 3.7-93.0\right)$, respectively, by spatial resolution of $5-\mathrm{km}$ grid-cell. The probable hourly precipitation by GUM is less than that of GEV with a shape parameter of less than 0.0. Our results demonstrate that R/A-based probable hourly precipitation and SWI by GUM, which has robust estimation, is appropriate for landslide hazard assessment. There results revealed the potential and limitation of estimating the probable precipitation from the R/A dataset. Further study should verify the $\mathrm{R} / \mathrm{A}$ dataset and the probable precipitations with accumulation of $\mathrm{R} / \mathrm{A}$.
\end{abstract}

(Citation: Saito, H., and H. Matsuyama, 2015: Probable hourly precipitation and Soil Water Index for 50-yr recurrence interval over the Japanese archipelago. SOLA, 11, 118-122, doi: 10.2151/sola.2015-028.)

\section{Introduction}

Radar/Raingauge-Analyzed Precipitation (R/A) has been operated by the Japan Meteorological Agency (JMA) since April 1988 for elucidating nationwide precipitation distribution and for preventing rainfall-related disasters across Japan (e.g., Shimpo 2001a). Actually, R/A is well-known as a high-resolution grid precipitation product based on radar observations calibrated using dense raingauge observations such as the Automated Meteorological Data Acquisition System (AMeDAS). This unprecedented detailed precipitation dataset, which has been accumulated for more than $25 \mathrm{yr}$, enables statistical discussion of quasi-climatic rainfall conditions over the Japanese archipelago.

During the warm season, heavy rainfalls occur every year, causing hazardous landslides and floods. The Japanese Government has therefore operated a nationwide early warning system for landslide disasters since 2005, based on hourly precipitation ( $\mathrm{mm}$ $\mathrm{h}^{-1}$ ), and a Soil Water Index (SWI, see Supplement 1) derived from R/A (Okada et al. 2001; Osanai et al. 2010). Recently, the importance of probable precipitations for landslide hazard assessments has been recognized (e.g. Kobayashi 2006). For example, a nationwide landslide inventory shows that the recurrence interval of heavy rainfall associated with a large landslide is more than 40-yr in Japan (Saito et al. 2014). Since 2013, JMA has operated Emergency Warnings for heavy rainfall based on rainfall indices

Corresponding author: Hitoshi Saito, Kanto Gakuin University, 1-50-1, Mutsuura-Higashi, Kanazawa, Yokohama, Kanagawa 236-8501, Japan. E-mail: hsaito@kanto-gakuin.ac.jp. (C)2015, the Meteorological Society of Japan. and SWI for a 50-yr recurrence interval (JMA 2013; Saito et al. 2013). However, few studies have discussed the 50-yr recurrence intervals of the landslide-related rainfall indices derived from the $\mathrm{R} / \mathrm{A}$ dataset. Validating the probable hourly precipitation and SWI for a 50-yr recurrence interval along with these uncertainties is therefore important for landslide hazard assessment.

Previous studies also analyzed probable precipitations over the Japanese archipelago based on raingauge datasets (e.g., Ninomiya 1977; Matsumoto 1989; Toyama and Mizuno 2002; Kobayashi 2006; Miyajima and Fujibe 2011). Although these raingauge datasets include long-term records, their spatial resolution is insufficient to assess landslide hazards, especially in mountainous areas.

We address these problems using a high-resolution nationwide 26-yr (1988-2013) R/A dataset. Although weather radar data generally have limited homogeneity caused by continual improvements to the data processing algorithms (Durrans et al. 2002), their marked advantage is their higher spatial resolution (e.g., Overeem et al. 2009). Our objective is to produce a preliminary probable hourly precipitation and probable SWI for a 50-yr recurrence interval from the 5-km grid-cell R/A dataset over the Japanese archipelago. To date, the selection of a probability density function (PDF) along with the characteristics of their parameters has been investigated in Japan from a statistical perspective, such as fitness, bias, and uncertainty of a Gumbel distribution (GUM) and/or a generalized extreme value distribution (GEV) (Fujibe 2014; Kuzuha 2015). This study, in turn, discusses these PDFs and probable precipitation from $\mathrm{R} / \mathrm{A}$ to application of landslide disaster prevention, which shall certainly contribute to new aspects of the study of probable precipitation.

\section{Data and methods}

We analyzed hourly R/A datasets from April 1988 through December 2013. The spatial resolution of $\mathrm{R} / \mathrm{A}$ was changed from $5-\mathrm{km}$ to $2.5-\mathrm{km}$ in April 2001, and from $2.5-\mathrm{km}$ to $1-\mathrm{km}$ in January 2006 along with changes in data processing algorithms. We therefore verified the homogeneity of the 26-yr time series following three steps.

First, we re-arranged the R/A after April 2001 to spatial resolution of ca. $5-\mathrm{km}$ (longitudinal $0.0625^{\circ} \times$ latitudinal $0.05^{\circ}$ ) following Nagata and Tsujimura (2006) and Urita et al. (2011). The modified 5-km R/A dataset after 2001 had the same spatial resolution and the same location as that before April 2001. This $5-\mathrm{km} \mathrm{R} / \mathrm{A}$ dataset, which is regarded as continuous (Nagata and Tsujimura 2006; Urita et al. 2011), is used to calculate SWI by JMA (Osanai et al. 2010). We also calculated SWI from the hourly 5-km R/A dataset applying the same method of JMA.

Secondly, we selected 19,806 grid points that have record period $\geq 23 \mathrm{yr}$ around the Japanese archipelago (Figs. 1a, d). Among these, 18,289 grid points (92.3\% of the study area) have a record period of 26-yr (Fig. 1d). Spatial averages of annual precipitations obtained from R/A (Fig. 1a) and from the climate mesh data (1981-2010) of JMA (Fig. 1b) were, respectively, $2,046.1 \mathrm{~mm} \mathrm{yr}^{-1}$ and 1,751.0 $\mathrm{mm} \mathrm{yr}^{-1}$. Although R/A overestimates long-term precipitation (Fig. 1c), its short-term (hourly precipitation) quality is high because R/A is designed for disaster-prevention activities (Shimpo 2001b; Kamiguchi et al. 2010). For example, R/A overestimated accumulated precipitation by 

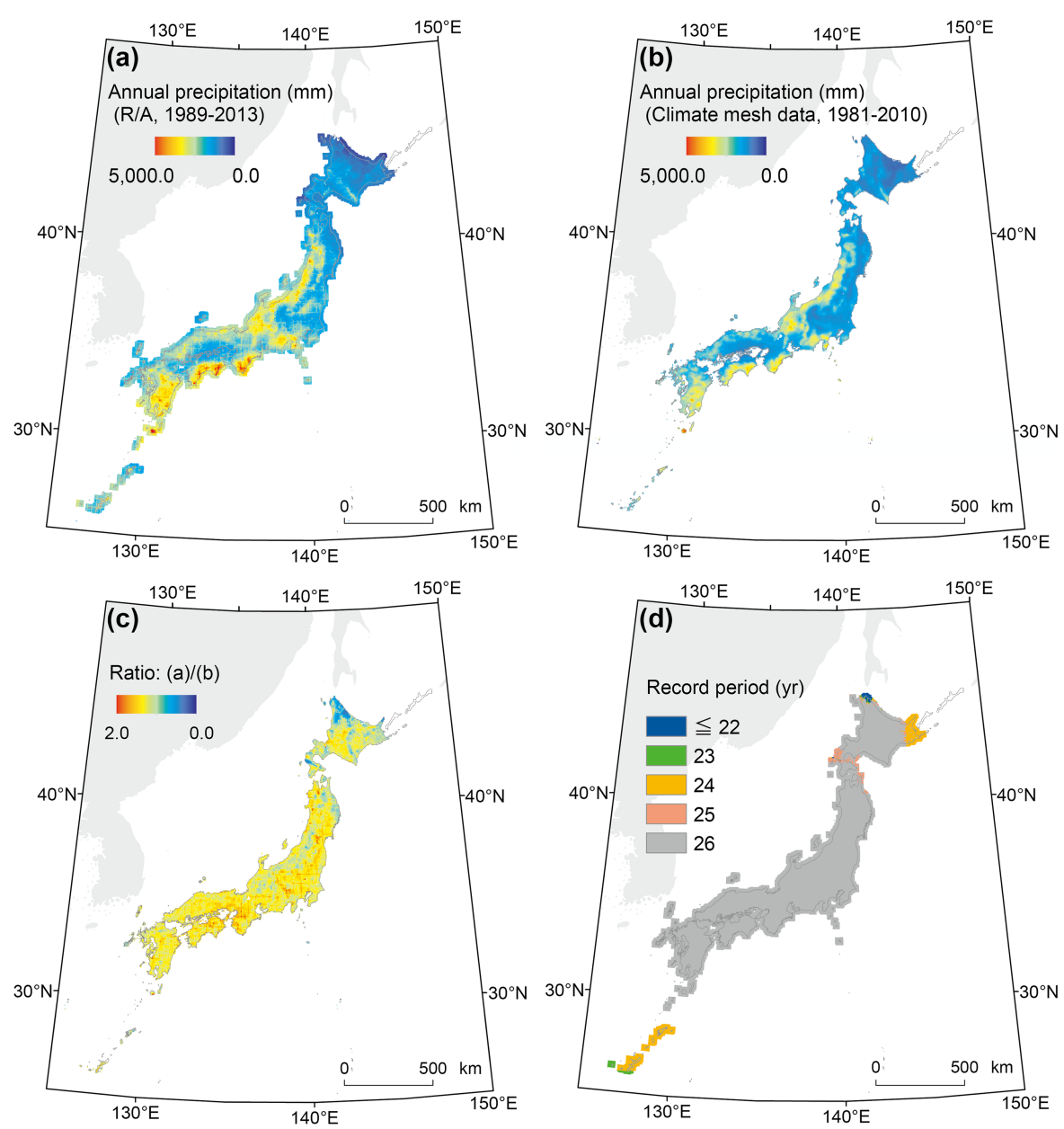

Fig. 1. Annual precipitations calculated using (a) R/A during 1989-2013, and using (b) Climate mesh data of JMA during 1981-2010: (c) shows the ratio of (a)/(b): (d) depicts the record period of R/A.

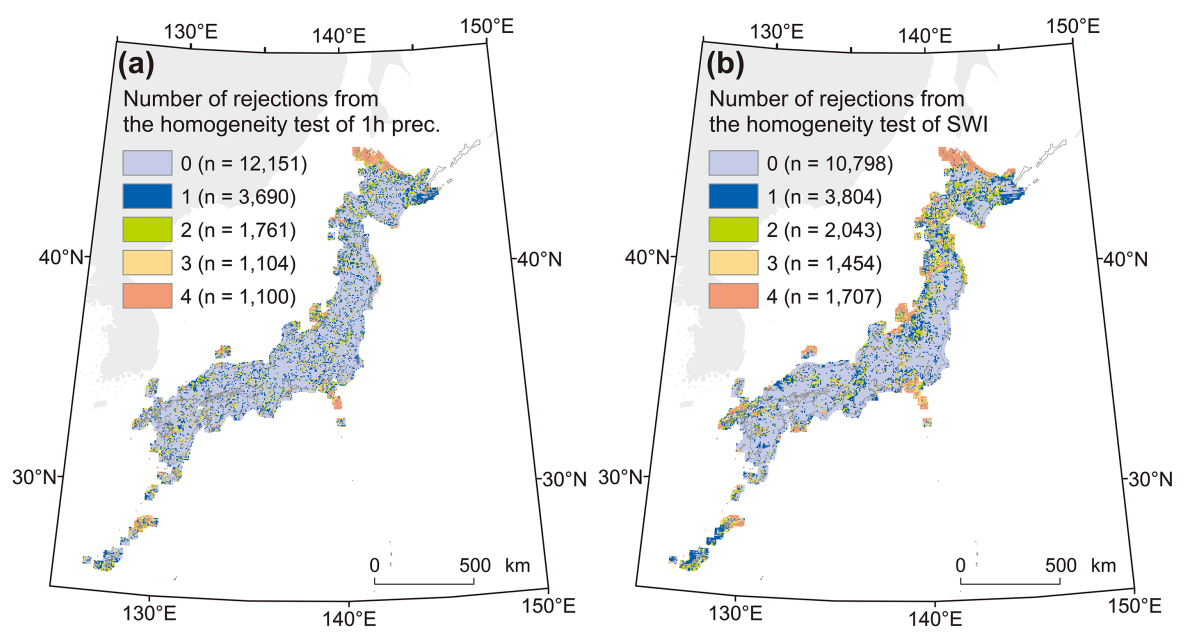

Fig. 2. Number of rejections from the homogeneity test of Wijngaard et al. (2003) at the $5 \%$ level for the 26-yr time series of (a) annual maximum hourly precipitation and (b) annual maximum SWI.

14\% during 1995-2004 (Wakazuki et al. 2007).

Thirdly, we adopted the homogeneity test of Wijngaard et al. (2003) for the 26-yr time series of the R/A dataset. Urita et al. (2011) confirmed the homogeneity of the time series based on the daily maximum precipitation. The time series of the daily maximum precipitation from the $5-\mathrm{km} \mathrm{R} / \mathrm{A}$ dataset shows the same trend of the interannual variation from that of AMeDAS.
This study further confirmed the homogeneity of the 26-yr time series of the maximum hourly precipitation and the maximum SWI (Fig. 2). We calculated the maximum hourly precipitation and maximum SWI of each calendar year for each grid point of 1988-2013. Most of the maximum hourly precipitation occurred during the warm season. Therefore, the hydrological year is set as the calendar year. Missing data were replaced with $0.0 \mathrm{~mm}$ 
$\mathrm{h}^{-1}$ in the calculation. The homogeneity test comprises four tests using statistics related to (1) standardized data, (2) summation of anomaly data, (3) summation of ranks, and (4) the relation between interannual variability and variance of the data. The null hypothesis is that the time series is not non-homogeneous. Figure 2 shows that 17,602 grid points $(88.9 \%$ of the study area) for hourly precipitation, and 16,645 grid points $(84.0 \%$ of the study area) for SWI have rejections of fewer than three at the 5\% level, which demonstrates the significant homogeneity of these time series (Wijngaard et al., 2003). Although 19,806 grid points were analyzed in this study, we discuss the statistics calculated using homogeneous grid points alone $(n=17,602$ for hourly precipitation and $n=16,645$ for SWI).

Using the obtained 26-yr (1988-2013) time series of maximum hourly precipitation and maximum SWI at each grid point, we calculated the probable hourly precipitation and SWI of the 50 -yr recurrence interval. In general, a recurrence interval of a maximum value during the record period is approximately twice the period based on a Cunnane plot (Kobayashi 2006). This indicates twice the recorded period is acceptable for the recurrence interval. We also adopted L-moments to calculate the summary statistics for probability distributions (Hosking 1990). Recently, the use of L-moments has become more popular than other methods to estimate distribution parameters from the pooled annual maxima, and to calculate the probable precipitation because of the robust estimate for a given amount of data (e.g., Overeem et al. 2009; Fujibe 2014).

As a PDF, only GUM (extreme-value type I with two parameters) and GEV (with three parameters) were selected based on fitness analysis for selecting PDFs in Japan (Fujibe 2011, Eq. 1). Regarding GUM, some biases might arise, although its estimation is robust. For GEV and other PDFs with three parameters, the estimation is distributed around the true value at which the estimation varies widely. It is therefore sufficient to treat GEV alone as a representative of PDFs with three parameters (Fujibe 2011). The cumulative distribution functions of GEV and GUM are defined respectively as follows.

$$
\begin{aligned}
& F(x)=\exp \left\{-\left(1-\frac{\kappa(x-\beta)}{\alpha}\right)^{1 / \kappa}\right\}, \quad(\kappa \neq 0) \\
& F(x)=\exp \left\{-\exp \left(-\frac{x-\beta}{\alpha}\right)\right\}, \quad(\kappa=0)
\end{aligned}
$$

Here, $\alpha, \beta$, and $\kappa$ respectively denote the scale parameter, the location parameter, and the shape parameter, as calculated from L-moments. $\kappa=0$ corresponds to GUM.

The calculation of recurrence intervals longer than the record period introduces uncertainty (e.g., Fujibe 2011). This study adopted the jackknife (leave-one-out) method on the 26-yr time series to assess inherent uncertainties and robustness of the estimation. We then validated histograms of the estimated values using GUM and GEV, and jackknife standard deviations $\left(\Delta P^{*}\right)$ estimated as follows.

$$
\Delta P^{*}=\sqrt{N-1} * \Delta P
$$

Here, $N$ and $\Delta P$ respectively represent the record period and the standard deviation of the $N$ jackknife estimations at each grid point. The jackknife standard deviation shows the error of the estimation (Tung and Mays 1981; Takara and Takasao 1988; Fujibe 2011)

\section{Results}

Figure 3 displays the probable hourly precipitation and SWI of the 50-yr recurrence interval with a $5-\mathrm{km}$ grid-cell. Ranges of the probable hourly precipitations are $17.0-158.0 \mathrm{~mm} \mathrm{~h}^{-1}$ in GUM, and 16.8-186.4 $\mathrm{mm} \mathrm{h}^{-1}$ in GEV (Figs. 3, 4). The jackknife standard deviation range by GUM is $1.1-51.1 \mathrm{~mm} \mathrm{~h}^{-1}$ with average of $7.8 \mathrm{~mm} \mathrm{~h}^{-1}$, whereas that by GEV is $0.8-84.9 \mathrm{~mm} \mathrm{~h}^{-1}$ with average of $10.8 \mathrm{~mm} \mathrm{~h}^{-1}$ (Fig. 4c) which show the uncertainty of estimations. The jackknife standard deviation by GUM is less than that of GEV, which agrees well with results reported by Fujibe (2011).

The probable hourly precipitation exhibits a ten-fold difference in the Japanese archipelago. These spatial patterns depict a latitudinal gradient: smaller values are concentrated in the northeastern part of Hokkaido, but larger values are concentrated along the Pacific coast of western Japan (Figs. 3a, b). However, these gradients are not monotonic, and the probable hourly precipitation shows detailed spatial patterns.

The spatial averages of the probable hourly precipitation are $68.2 \mathrm{~mm} \mathrm{~h}^{-1}$ in GUM, and $69.6 \mathrm{~mm} \mathrm{~h}^{-1}$ in GEV. Estimation by GEV yields slightly larger results than those by GUM (Fig. 4a), which is statistically significant at the $5 \%$ level. In terms of PDF, GUM has larger positive skewness than GEV does (Fig. 5a). Therefore, during heavy rainfall events, GUM has larger numbers of grid points than GEV does, which exceed the probable hourly precipitation because of the shape parameter $(\kappa)$ of GEV (Eq. 1). Figure $5 b$ exhibits the accumulated frequency distribution of the probable hourly precipitation. The accumulated frequencies of GUM are systematically larger than those of GEV in bins of 40-100 $\mathrm{mm} \mathrm{h}^{-1}$. Results of the present analysis show that the shape parameter $(\kappa)$ of GEV is less than 0.0 at many grid points, thereby producing the characteristics presented in Fig. 5 .

The probable SWI of the 50-yr recurrence interval by GUM and GEV (Figs. 3c, d) also depict the detailed spatial patterns, which mimics those of the probable hourly precipitation (Figs. 3a, b). Ranges of the probable SWI are 82.1-638.6 with average of 226.9 in GUM (Fig. 3c), and 68.6-705.0 with average of 221.8 in GEV (Fig. 3d). Regarding the probable SWI, estimations conducted by GUM and GEV yield similar results (Fig. 4b). However, the jackknife standard deviation by GUM is also smaller than that of GEV (Fig. 4d). The range by GEV is $2.4-183.0$ with average of 25.7, whereas that by GUM is 3.7-93.0 with average of 19.6 .

\section{Discussion}

\subsection{Spatial pattern of the probable hourly precipitation and SWI}

Toyama and Mizuno (2002) calculated the probable hourly precipitation from the AMeDAS dataset of 1979-2000 based on a regional frequency analysis that uses data from several groups of sites to estimate the frequency distribution (Hosking and Wallis 1993, Fig. 3e). Although the nationwide spatial pattern of the probable hourly precipitation estimates from AMeDAS (Toyama and Mizuno 2002, Fig. 3e) roughly mimics that from R/A (Figs. 3a, b), the estimates from R/A tend to be larger than those from AMeDAS (Fig. 6). These differences reach several tens of millimeters per hour which might be caused by the difference of dataset, such as overestimations included in the R/A dataset (Kamiguchi et al. 2010). Other candidates are statistical periods, regional frequency analysis, and the uncertainty of estimation in Toyama and Mizuno (2002) and in this study (Fig. 4c).

The advantage of R/A is its higher spatial resolution. The regional patterns of the probable hourly precipitation with $5-\mathrm{km}$ grid-cell are far from monotonic links between probable precipitations from AMeDAS (Fig. 3f). The spatial distribution of AMeDAS is insufficient to assess regional landslide hazards, especially in mountainous areas. For example, Typhoon Talas in 2011 caused heavy rainfall and catastrophic landslides in the Kii Peninsula where AMeDAS locations were only $\sim 20$ stations (Fig. 3f). Spatial distributions of these landslides were related to the historical records of heavy rainfall based on the $5-\mathrm{km} \mathrm{R} / \mathrm{A}$ dataset (Saito and Matsuyama 2012) which demonstrated the importance of the probable precipitation with high spatial resolution. The Pacific coastal areas of western Japan are also characterized by a high density of landslide occurrence attributable to heavy rainfall (Saito et al. 2014). The R/A-based high resolution probable hourly precipitation and SWI enable a landslide hazard assessments in these landslide-prone areas. 

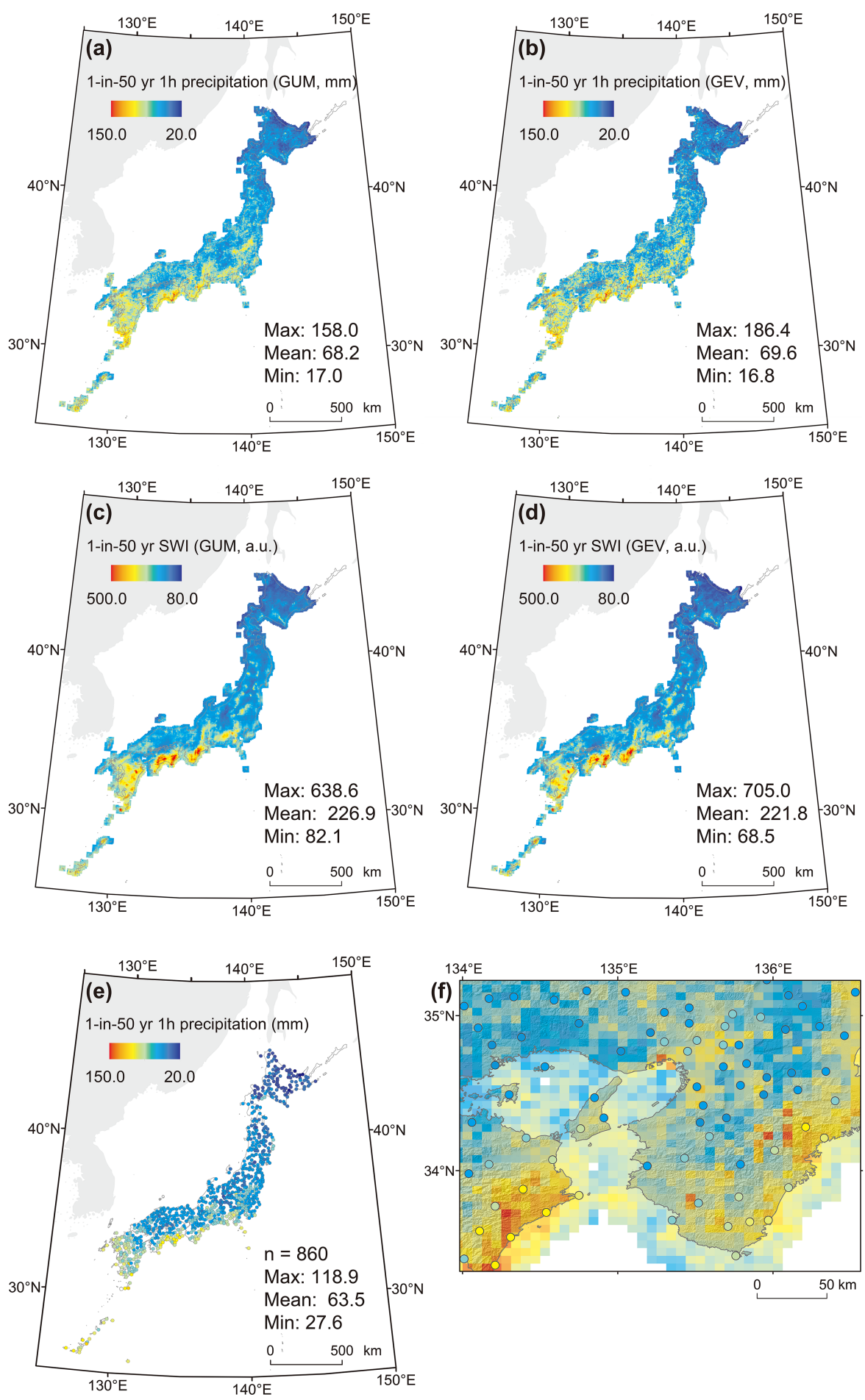

Fig. 3. (a, b) Probable hourly precipitation $\left(\mathrm{mm} \mathrm{h}^{-1}\right)$ and (c, d) probable SWI (arb. unit) of the 50-yr recurrence interval. (a) and (c) are calculated using GUM, whereas (b) and (d) are calculated using GEV. These figures show 19,806 grid points which have a record period of R/A $\geq 23$ yr. (e) shows the probable hourly precipitation of a 50-yr recurrence interval calculated using the AMeDAS dataset provided by Toyama and Mizuno (2002). (f) The probable hourly precipitation from R/A using GUM (grids, a) and from AMeDAS (circles, e) around the Kii Peninsula; color scales are the same as those for panels (a), (b), and (e); background shows the relief map derived from 2.25" by 1.5" DEMs of the Geospatial Information Authority of Japan.

\subsection{Characteristics of GUM and GEV}

The probable hourly precipitation by GUM is less than that of GEV with the shape parameter $(\kappa)<0.0$ (Fig. 5a). The lower probable precipitation is applicable for a safer rainfall threshold of disaster prevention. Another benefit of GUM is that it incorporates only two parameters (location and scale parameters, Eq. 1). Therefore, the analysis of the large-scale distribution of extreme value parameters for precipitation over the Japanese archipelago can be simplified (Fujibe 2014). Moreover, it is better to apply the same PDF to the same meteorological elements such as hourly precipitation (Suzuki 1980). Regarding probable precipitation, Suzuki (1980) also proposed the capture of regional differences and integration times by considering the characteristics of PDF parameters that are selected. The applicability of GUM in this study follows that proposed by Suzuki (1980).

The jackknife standard deviation by GUM is less than that by 

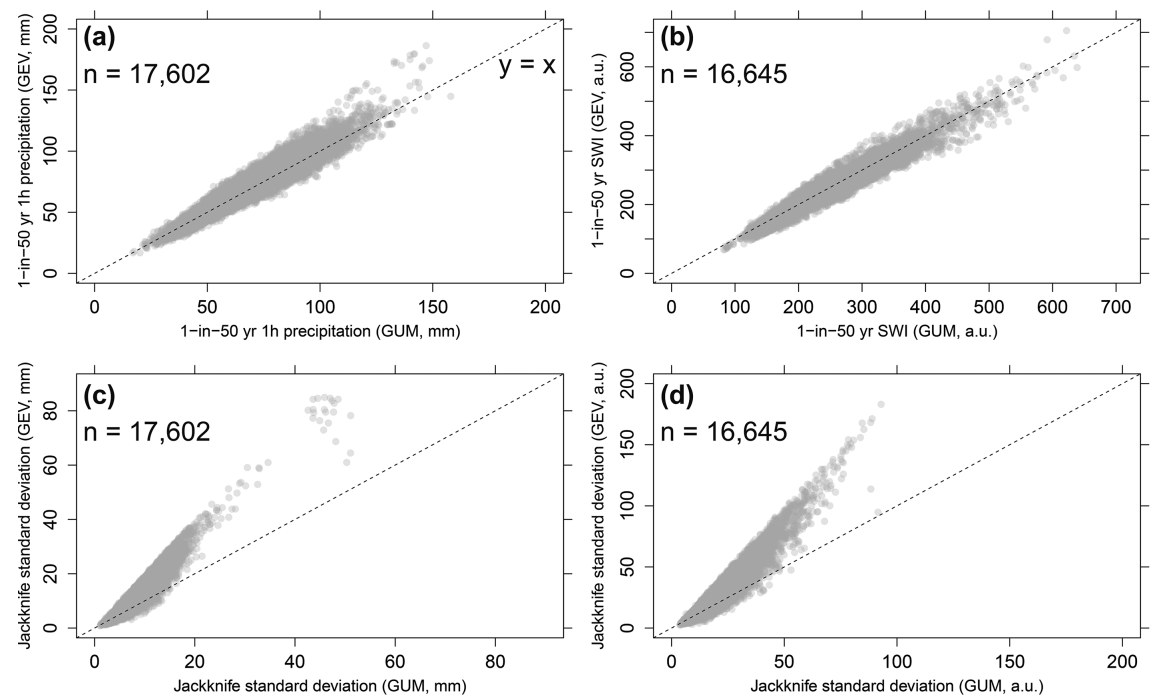

Fig. 4. Scatter diagram of (a) estimated probable hourly precipitation $\left(\mathrm{mm} \mathrm{h}^{-1}\right)$ : (b) estimated probable SWI (arb. unit) calculated using GUM and GEV. (c) and (d) are respectively equal to (a) and (b) but for jackknife standard deviations of the estimation.
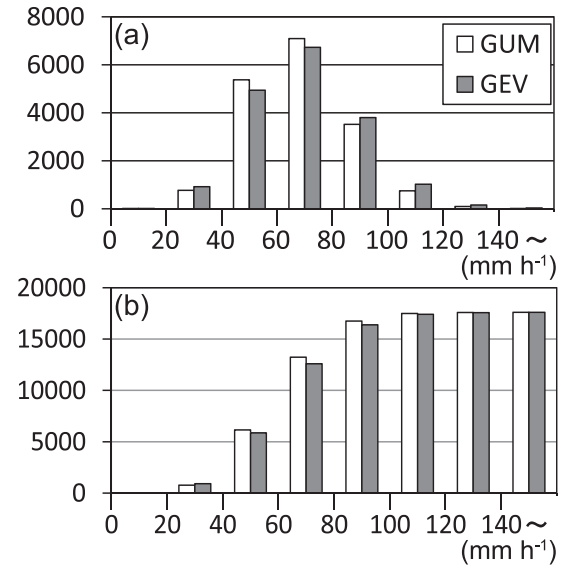

Fig. 5. (a) Histogram showing probable hourly precipitation of 50-yr recurrence interval over the Japanese archipelago, estimated using GUM (white) and GEV (gray): (b) same as (a) but for the accumulated histogram.

GEV (Figs. 4c, d). These results demonstrate that GUM is more robust than GEV in this study, although the former might have a bias (Fujibe 2011). Estimation by GEV is affected strongly by whether or not an extreme rainfall event is observed during 26 $\mathrm{yr}$ in a grid-cell with the shape parameter ( $\kappa$, Eq. 1$)$. To discuss the frequency of such extreme rainfall events, $26 \mathrm{yr}$ is an insufficiently long-term observation. Regarding the current R/A dataset, robust estimation by GUM, namely less susceptible estimation to an extreme event, is appropriate for landslide hazard assessment.

\subsection{Potential and limitation of $R / A$-based probable precipitation}

Probable precipitation has been estimated in Japan from the AMeDAS dataset, which has the important benefit of data quality and a long record period (e.g., Toyama and Mizuno 2002; Kobayashi 2006). Toyama and Mizuno (2002) adopted regional frequency analysis, which might produce less uncertainty of the estimation than other methods can. Kobayashi (2006) estimated probable precipitation using the AMeDAS dataset applying the jackknife method and standard least-square criterion (SLSC; Takara and Takasao 1988). Probable precipitation with a 1-km grid-cell was then calculated from interpolation of the sparse AMeDAS-based probable precipitations. However, the interpolation of precipitation entails great uncertainty, especially in
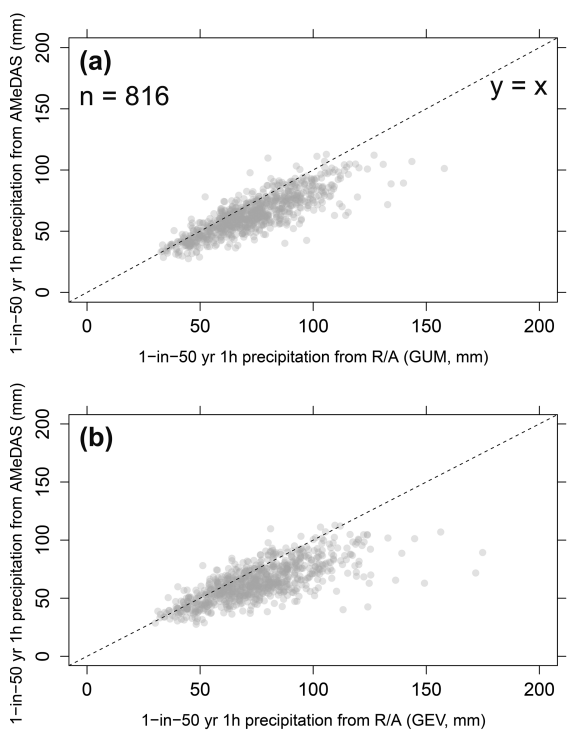

Fig. 6. Comparison of probable hourly precipitation of 50-yr recurrence interval calculated from the R/A dataset ( $x$-axis, this study) using (a) GUM and (b) GEV for homogeneous grid points, and from the AMeDAS dataset based on regional frequency analysis ( $y$-axis, Toyama and Mizuno 2002).

mountainous areas.

As described above, the salient advantage of the R/A dataset over AMeDAS is its higher spatial resolution for disaster prevention. We refrained from using regional frequency analysis due to the difficulty of defining a group of sites from the gridded $\mathrm{R} / \mathrm{A}$ dataset. Although the R/A dataset involves some difficulties related to the limitation of the homogeneity, this study preliminarily estimated the probable hourly precipitation and SWI by applying the homogeneity test of Wijngaard et al. (2003).

Like any other studies (e.g., Toyama and Mizuno 2002), the estimation might bear inherent large uncertainties and bias due to the analyzed record period and the PDF selection (Fujibe 2011). Our probable hourly precipitation and SWI for a 50-yr recurrence interval from the 26-yr dataset also showed large uncertainty (Fig. 4). These jackknife standard deviations reached $8.5-15.3 \%$ of the estimated values on averages. Additional studies are necessary to evaluate the validity of the R/A dataset, to verify the probable precipitation and SWI for other recurrence interval, and to examine regional frequency analysis with accumulations of R/A datasets. 


\section{Conclusions}

We produced a preliminary high-resolution probable hourly precipitation and SWI for a 50-yr recurrence interval over the Japanese archipelago from a 26-yr R/A dataset. This study investigated the basic characteristics of these datasets from the viewpoint of disaster prevention. Our results revealed detailed spatial patterns of the probable hourly precipitation and SWI with $5-\mathrm{km}$ grid-cell, which enables nationwide landslide hazard assessment. The probable hourly precipitation by GUM is less than that of GEV with the shape parameter $(\kappa)<0.0$. Our results demonstrate that robust estimation by GUM is appropriate for landslide hazard assessment from the current R/A dataset. The estimated probable hourly precipitation and SWI also showed a large degree of uncertainty. Future studies should evaluate these characteristics along with validation of the R/A dataset for practical disaster prevention.

\section{Acknowledgements}

We appreciate constructive comments offered by Dr. F. Fujibe of Tokyo Metropolitan University related to an earlier version of the manuscript. We thank the corresponding editor, Dr. M. Sugi of Meteorological Research Institute, and two anonymous reviewers for their valuable comments. Thanks also are extended to Mr. $\mathrm{S}$. Urita of the Remote Sensing Technology Center of Japan for preparing 5-km grid-cell R/A used for this study. This study was partially supported by the Advanced Research Program of Asian Human Research Fund by Tokyo Metropolitan Government, along with Grants-in-Aid for Young Scientists (B) 15K16287 and for Scientific Research (B) 26282080 from the Japan Society for the Promotion of Science. AMeDAS-based probable precipitations were provided by Toyama and Mizuno (2002). We computed statistics using Hosking's L-moments implemented in R software (http://CRAN. R-project.org/package=lmom).

Edited by: M. Sugi

\section{Supplement}

Supplement 1. Soil Water Index

\section{References}

Durrans, S. R., L. T. Julian, and M. Yekta, 2002: Estimation of depth-area relationships using radar-rainfall data. J. Hydrol. Eng., 7, 356-367.

Fujibe, F., 2011: Discussion of fitness analysis for selecting distribution functions in extreme value analysis. Tenki, 58, 765775 (in Japanese with English abstract).

Fujibe, F., 2014: Large-scale distribution of extreme value parameters for precipitation in Japan. Tenki, 61, 81-90 (in Japanese with English abstract).

Hosking, J. R. M., 1990: L-moments: Analysis and estimation of distributions using linear combinations of order statistics. $J$. Roy. Stat. Soc., 52B, 105-124.

Hosking, J. R. M., and J. R. Wallis, 1993: Some statistics useful in regional frequency analysis. Water Resour. Res., 29, 271281.

JMA, 2013: Emergency Warning System. Available at http://www. jma.go.jp/jma/en/Emergency_Warning/ew_index.html (accessed 2015.4.1).

Kamiguchi, K., O. Arakawa, A. Kitoh, A. Yatagai, A. Hamada, and N. Yasutomi, 2010: Development of APHRO-JP, the first Japanese high-resolution daily precipitation product for more than 100 years. Hydrol. Res. Lett., 4, 60-64.

Kobayashi, K., 2006: Estimation of probable rainfall and the recurrence interval. Wea. Serv. Bull., 73, 51-72 (in Japanese).

Kuzuha, Y., 2015: Estimating optimal stochastic probability dis- tributions of daily precipitation considering return periods of the largest records. J. Japan Soc. Hydrol. Water Resour., 28, 59-71 (in Japanese with English abstract).

Matsumoto, J., 1989: Heavy rainfalls over east Asia. Int. J. Climatol., 9, 407-423.

Miyajima, J., and F. Fujibe, 2011: Climatology of extreme precipitation in Japan for different time scales. SOLA, 7, 157-160.

Nagata, K., and Y. Tsujimura, 2006: Characteristics of Radar/ Raingauge-Analyzed Precipitation and short-range precipitation forecast along with notices on their usage. Training Text of Quantitative Forecast in 2006, 9-24 (in Japanese).

Ninomiya, K., 1977: Distribution of precipitation over the Japan islands in relation to time-scale of heavy rainfalls. Tenki, 24, 63-70 (in Japanese).

Okada, K., Y. Makihara, A. Shimpo, K. Nagata, M. Kunitsugu, and K. Saito, 2001: Soil Water Index. Tenki, 48, 349-356 (in Japanese).

Osanai, N., S. Shimizu, K. Kuramoto, S. Kojima, and T. Noro, 2010: Japanese early-warning for debris flows and slope failures using rainfall indices with Radial Basis Function Network. Landslides, 7, 325-338.

Overeem, A., T. A. Buishand, and I. Holleman, 2009: Extreme rainfall analysis and estimation of depth-duration-frequency curves using weather radar. Water Resour. Res., 45, W10424, doi:10.1029/2009WR007869.

Saito, H., and H. Matsuyama, 2012: Catastrophic landslide disasters triggered by record-breaking rainfall in Japan: Their accurate detection with Normalized Soil Water Index in the Kii Peninsula for the year 2011. SOLA, 8, 81-84.

Saito, H., O. Korup, T. Uchida, S. Hayashi, and T. Oguchi, 2014: Rainfall conditions, typhoon frequency, and contemporary landslide erosion in Japan. Geology, 42, 999-1002.

Saito, K., T. Ota, and K. Takahashi, 2013: Early warning for record-breaking rainfall with the use of probable precipitation of the return period of 50 years. Tenki, 60, 405-411 (in Japanese).

Shimpo, A., 2001a: Radar/Raingauge-Analyzed Precipitation (I). Tenki, 48, 579-583 (in Japanese).

Shimpo, A. 2001b: Radar/Raingauge-Analyzed Precipitation (II). Tenki, 48, 777-784 (in Japanese).

Suzuki, E., 1980: A summarized review of theoretical distributions fitted to climatic factors and Markov chain models of weather sequences, with some examples. Ikeda, S., Ed., Statistical Climatology (Developments in Atmospheric Science, 13), 120.

Takara, K., and T. Takasao, 1988: Criteria for evaluating probability distribution models in hydrologic frequency analysis. $J$. Japan. Soc. Civ. Engrs., 393II, 151-160 (in Japanese with English abstract).

Toyama, N., and H. Mizuno, 2002: Daily and 1-hour precipitation for return periods of 2 to 1000 years at AMeDAS stations in Japan estimated from regional frequency analysis. J. Meteor. Res., 54, 55-100 (in Japanese).

Tung, Y. K., and L. W. Mays, 1981: Generalized skew coefficients for flood frequency analysis. Water Resour. Bull., 17, 262269.

Urita, S., H. Saito, and H. Matsuyama, 2011: Temporal and spatial discontinuity of Radar/Raingauge-Analyzed Precipitation that appeared in relation to the modification of its spatial resolution. Hydrol. Res. Lett., 5, 37-41.

Wakazuki, Y., S. Kanada, C. Muroi, A. Hashimoto, T. Kato, M. Nakamura, A. Noda, M. Yoshizaki, and K. Yasunaga, K. 2007: Regional climate projection experiments on the Baiu frontal activity around the Japan islands using a nonhydrostatic cloud-system-resolving model. J. Earth Sim., 8, $13-25$.

Wijngaard, J. B., A. M. G. Klein Tank, and G. P. Können, 2003: Homogeneity of 20th century European daily temperature and precipitation series. Int. J. Climatol., 23, 679-692.

Manuscript received 29 July 2015, accepted 16 September 2015 SOLA: https://www.jstage.jst.go.jp/browse/sola/ 